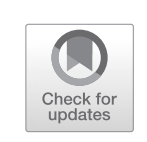

\title{
9
}

\section{Conclusion: Reflections on the First Five Years of the Prevent Duty in Early Years, Primary, Secondary and Further Education}

\author{
Lee Jerome, Joel Busher, Megan A. Armstrong, \\ Tufyal Choudhury, Raquel da Silva, Alex Elwick, \\ Giuditta Fontana, Natalie James, James Lewis, \\ Jenny Robson, Hans Svennevig, and Paul Thomas
}

\begin{abstract}
This chapter reflects on the key conclusions from across the previous chapters. First, it discusses how the Prevent Duty has become normalised in schools, colleges and early years provision, as professionals incorporated it into existing structures and processes-both in the curriculum and through safeguarding. Second, it discusses how, whilst some professionals might have unconsciously reproduced potentially harmful stereotypes and simplistic assumptions about terrorism and extremism, others have consciously worked to mitigate the possible negative effects of the Duty, and have used the curriculum to further develop values education and opportunities for critical discussion. Third, the chapter reflects on the implications of the apparent banalisation of Prevent within education, and how this may or may not intersect with processes of securitisation.
\end{abstract}

\footnotetext{
L. Jerome $(\bowtie)$

Department of Education, Middlesex University, London, UK e-mail: 1.jerome@mdx.ac.uk 
Keywords Prevent Duty $\bullet$ Normalisation $\bullet$ Banalisation $\bullet$ Securitisation

- Safeguarding

J. Busher

Centre for Trust, Peace and Social Relations, Coventry University, Coventry, UK e-mail: joel.busher@coventry.ac.uk

M. A. Armstrong

Liverpool John Moores University, Liverpool, UK

e-mail: M.A.Armstrong@ljmu.ac.uk

T. Choudhury

Durham Law School, Durham University, Durham, UK

e-mail: t.a.choudhury@durham.ac.uk

R. da Silva

University of Birmingham, Birmingham, UK

Centre for International Studies, ISCTE-IUL, Lisbon, Portugal e-mail: R.B.P.daSilva@bham.ac.uk

A. Elwick • H. Svennevig

UCL Institute of Education, London, UK

e-mail: a.elwick@ucl.ac.uk; h.svennevig@ucl.ac.uk

G. Fontana

University of Birmingham, Birmingham, UK

e-mail: g.fontana@bham.ac.uk

N. James

School of Politics and International Studies, University of Leeds, Leeds, UK e-mail: ptnj@leeds.ac.uk

J. Lewis

Department of Politics, Philosophy and Religion, Lancaster University, Lancaster, UK

e-mail: j.lewis8@lancaster.ac.uk

J. Robson

Cass School of Education and Communities, University of East London, London, UK

e-mail: j.robson@uel.ac.uk 
Our decision to write this book was motivated by the belief that if we as a society are to have a meaningful conversation about the Prevent Duty and the wider Prevent strategy, then we need to be better informed about how the Duty has played out on the ground since it was introduced in 2015. In order to develop such an understanding, it is important to get beyond, although not to discard or overlook, high-level policy and theoretical analysis, and to explore the experiences of the educators, students and other actors whose lives are being influenced directly by the Duty. In this final short chapter we draw out some of the main insights from across the preceding chapters. We organise this discussion around the three basic focal points for analysis that run throughout the book: the enactment, impacts and implications of the Prevent Duty.

\section{The Enactment of the Prevent Duty}

Perhaps the most striking theme here concerns the Duty's rapid normalisation within education. Throughout the volume, the picture that emerges is, for the most part, one of the Duty quickly coming to be seen as just another of the many requirements placed on educators. While it initially caused considerable anxiety, in general the Duty appears to have become a 'non-exceptional' area of practice for many education professionals (see especially Chap. 7).

All of the chapters indicate that the UK government's framing of the Duty as a straightforward extension of existing safeguarding responsibilities has largely been accepted by educators, despite criticisms by a number of academics that the extension of this concept potentially pathologises and closes down dissent, and is likely to focus disproportionately on Muslim students (see Chap. 2). Nevertheless, occasional disruptions to this policy frame in the course of educators' own reflective practice indicate there are still some unresolved tensions in this 'Prevent-as-safeguarding' narrative (see Chaps. 3 and 8). Chapters 5, 6, 7, and 8 also illustrate how the

\section{P. Thomas}

Huddersfield Centre for Research in Education and Society (HudCRES), University of Huddersfield, Huddersfield, UK

e-mail: d.p.thomas@hud.ac.uk 
common framing of the Duty as 'safeguarding' obscures the very different implications for each age-related phase of education. In practice, safeguarding in the early years context is rather different from the further education sector and so, therefore, the Prevent Duty leads to quite distinctive practices related to surveillance and reporting. For example, among early years practitioners, particular emphasis appears to have been placed on increased surveillance of the families of children in their care (Chap. 5).

What the chapters also reveal is how quickly staff moved from feelings of anxiety about the Duty to the type of policy problem solving typical of 'street-level bureaucrats' (Lipsky, 2010). They examined the new requirements, 'mapped' how these requirements fitted with their existing practice, identified where their existing practices would require adaptation in order ensure compliance, and some explored opportunities the Duty might offer to pursue new projects or priorities. In other words, and at risk of over-simplification, while this rapid normalisation of the Prevent Duty has partly been a product of 'top-down' policy processes, it has also been a product of the way educators themselves have integrated it into existing professional practices and organisational cultures.

This rapid normalisation of the Duty has had important implications for how it has played out in practice. Most obviously, it has contributed to soften professional reticence about, or opposition to, the Duty. There has not been the widespread resistance to the Duty that one might have expected given the breadth and intensity of the criticism expressed prior to its introduction. Indeed, the chapters in this volume report that there has even been some positive acceptance. However, there is evidence of some continued professional wariness about, and resistance to, the Duty. This is particularly concentrated around the requirements to promote fundamental British values. Here, despite significant continuity with an existing pedagogical and organisational focus on values, the emphasis placed on the supposed Britishness of these values was often, although not unanimously, seen as being problematic, and quite possibly counter-productive-whether in terms of fostering potentially toxic in-group and out-group categories, or producing a narrow and somewhat impoverished discourse and understanding about positive values (see especially Chap. 5). There is also some evidence that concerns about the Duty are more prevalent among black and minority ethnic educators who, perhaps, might be more attuned to the Duty's potential to reinforce forms of structural racism (see Chap. 3). 


\section{The Impacts of the Prevent Duty}

It is important to note how challenging it is to identify and demonstrate with confidence the impacts of the Prevent Duty per se, without reaching well beyond the data. In particular, it is often difficult to disentangle the effects of the Duty from those of wider developments both within the education sector and within society more broadly (see especially Chaps. 7 and 8). Nonetheless, the kind of 'low-hovering research' (Anderson, 2007) presented in this volume offers a number of insights that are likely to be of interest to researchers, policymakers, civil society groups and educators alike.

What these accounts of the Prevent Duty really have in common is that they all paint a picture of considerable ambivalence: seemingly defying easy summarisation. In terms of the impact of the Duty on professional practice, the evidence indicates that most educators perceive the Duty to have had relatively little impact, either because they perceived it to be broadly commensurate with existing practices, or due to subtle forms of resistance, such as continuing to talk about 'our values' or 'school values' rather than 'fundamental British values'. Yet as discussed in Chap. 1, there was, at least initially, a marked increase in Prevent referrals after the Duty came into force; approximately a third of Prevent referrals have continued to come from the education sector, and despite the general narratives of continuity, across the chapters there is also evidence of considerable professional adaptation and innovation.

In terms of whether the Duty has had a 'chilling effect' on the voices of children and young people, there is a fairly consistent finding that staff are broadly confident in their ability to mitigate its possible negative effects. Indeed, there is evidence that some educators have seen the Duty as an opportunity to encourage greater dialogue around issues previously considered too sensitive or contentious, and to reprioritise areas of work that, until recently, would broadly have fallen under citizenship education. Some of the data raise questions about the extent to which such perceptions among staff resonate with the lived experience of children and young people, and particularly those of Muslim and other minority ethnic or religious backgrounds (see especially Chap. 8). 
What does seem to be clear from the evidence from secondary students (Chap. 4) is that young people want their teachers to create the space for open and critical investigation of issues related to terrorism and extremism. However, the resources endorsed by government for use in the classroom (reviewed in Chap. 4) fall considerably short of the kind of education requested by the students, which underlines the challenge for teachers in selecting, supplementing and interpreting such material (see Chap. 8). This raises important questions about whether it might be preferable for the UK government simply to re-emphasise such areas of work (e.g., learning about terrorism, extremism and the fundamental British values, but also about positive citizenship and democratic processes and values) within national curricula, rather than covering them separately under the rubric of Prevent. Bajaj (2012) has noted that curriculum content can be transformed by the context in which it is encountered, and so it may well be significant if concepts such as democracy, liberty and toleration are largely learned through British values and Prevent, rather than a broader form of critical citizenship education (Vincent, 2019).

The evidence about the possible link between the Prevent Duty and the stigmatisation of Muslim children and young people is also difficult to decipher. There appear to be fairly widespread perceptions that this risk exists, and both adults and young people recognise that their relationships and experiences are influenced by a wider context of substantial and persistent anti-Muslim racism and prejudice. The data discussed in this book demonstrate the potential for staff risk-assessments and referrals to be shaped by unconscious bias. They also indicate important variation in terms of the degree to which educators are confident that such risks can be effectively managed.

\section{The Wider Implications of the Prevent Duty and of Our Research}

In turning to consider the implications of our research we have to move beyond the data and assert our own interpretations of what they might mean. We suggest this research raises two points of particular importance 
for thinking about the Prevent Duty. First, the descriptions of the Duty set out in this volume lend considerable support to the idea that it should be understood within the context of ongoing processes of professional responsibilisation that are central to the expansion of neo-liberal forms of governance (Garland, 1996; Thomas, 2017). While policymakers might well argue that the Duty places legal responsibility on institutions rather than individuals, it would suggest a rather naive understanding of systems of power and accountability within contemporary professions to argue that the Duty has not placed greater responsibility and pressure on individuals. While responsibility for the Duty is felt particularly keenly by members of staff with specific safeguarding responsibilities (Chap. 3), it seems clear that these responsibilities have been internalised by educators more broadly, and that this has had a significant bearing on their lived experience. There is also evidence that educators often locate responsibility for the apparent failures of the Duty-whether in terms of missing 'genuine cases' or inappropriate referrals or other practices—with the individuals and institutions that have 'done it badly' (Chap. 3), rather than with higher-level processes of policy design and implementation. It seems reasonable to expect that this has had a major bearing on professional evaluations of the Duty.

The second point is about how the introduction of the Duty is shaping wider policy and public debates about Prevent and the UK's CounterTerrorism Strategy (CONTEST). If the broad accommodation of the Prevent Duty by a substantial majority of the educators in this volume reflects a general phenomenon across the half a million educators in Britain, this would appear to lend considerable weight to Heath-Kelly and Strausz's (2019) argument that we might be witnessing a 'banalisation' of counter-terrorism (see also Awan, Spiller, \& Whiting, 2018; McGlynn \& McDaid, 2019).

It remains unclear however what the implications of this banalisation will be. As Heath-Kelly and Strausz argue, if those responsibilised under the Duty internalise its logic and become less inclined to critically engage with this and similar legislation it might be seen as a source of concern. On this view we might expect that they will become more likely to slip into practices that both exacerbate structural racism and expand surveillance in ways that could seriously constrain free speech and undermine 
human rights. Yet it seems that other effects of this banalisation are also possible. This is because, at the same time as the counter-terrorism logics inscribed in the Prevent Duty come to permeate other areas of practice, including those related to education and childcare, prior practices and logics operating in these other spaces might also begin to shape the practice of the Prevent Duty and Prevent policy more generally. As Prevent becomes something banal, direct opposition might diminish, but so too might the accompanying sense of intimidation, anxiety and insecurity among professionals that is likely to distort their professional judgement and foster discriminatory practices. The banalisation of Prevent might also result in education and childcare professionals feeling increasingly emboldened to develop their own take on the Duty and to mould it around their own existing professional and institutional cultures and ethos, in the context of their wider relationships with families and communities. As this happens in early years provision, schools and colleges across the country, it is possible that grassroots policy enactment by education and childcare professionals could not only significantly reconfigure what the Prevent Duty looks like in educational settings, but might also give rise to important 'bottom-up' policy innovations that have wider implications for how societies seek to respond to issues such as polarisation, terrorism and political violence.

\section{Final Thoughts}

The picture that we have traced of the Prevent Duty in early years, primary, secondary and further education is one characterised by significant ambivalence. These findings do not lend themselves easily to claims that, as some critics of Prevent would have it, the Duty is a major threat to a cohesive, democratic and fair society. Yet neither do they lend themselves to claims that the problems that the Prevent Duty throws up can simply be addressed through a little more training and support. Such findings do not translate easily into policy recommendations. What they do, however, is provide an important reminder, should one be needed, that policy plays out in complex and often surprising ways as it travels from initial intention into practice (Ball, Maguire \& Braun, 2013). Policies 
concerned with countering and preventing violent extremism are no different. If we are serious about wanting to understand the effects of such policies, we must get as close as possible to where they are being put into practice, and we must be willing to grapple with a messy reality that might not fit comfortably, if at all, with our expectations.

We would argue that the accounts of this messy reality set out in this book also indicate that the educational debate about Prevent might usefully be expanded beyond the issues of securitisation, responsibilisation and the erosion of professional boundaries that have tended to dominate discussion to date, important though these remain. The first distinctively educational issue to emerge concerns what children and young people need to learn about terrorism and extremism, in order to feel that they understand the issues (including the threats and the policies designed to counter those threats). Teachers and other professionals are well-placed as trusted adults to play a role in building this level of critical understanding and to engage children and young people in various forms of values education, but it seems that policy could do more to empower them to undertake this fundamental educational role. Some of the educators in this research across all age-phases continue to question whether the framing of such knowledge as the 'promotion' of 'fundamental British values' is the most useful way to articulate what children and young people should learn. In practical terms, such framing seems to be alienating (at least some) professionals from the policy, even when they are generally well-disposed to the Prevent Duty as a whole.

The second educational issue relates to the nature of safeguarding. Here staff seem to have taken steps to integrate the Prevent Duty into existing safeguarding practices, and yet they also report concerns that the surveillance and monitoring of Muslim and minority ethnic students might reflect unconscious bias and prejudice. There is also evidence that some referrals are motivated by fears of being judged to have missed something, rather than being solely rooted in individual safeguarding concerns for children and young people. We note that the number and profile of referrals is shifting over time, and so this is an open question about whether the Duty encourages over-reporting, especially of some groups, or whether this is settling down as the policy becomes normalised. However, our research indicates that, even where the Prevent Duty has 
been absorbed into existing safeguarding practices, there are on-going concerns that such practices continue to be disproportionately focused on children and young people from specific ethnic or religious minorities, even where staff actively seek to mitigate against such effects. We believe therefore that some sort of equality impact review might be a useful next step in the policy's development.

As Chap. 2 indicated, the Prevent policy has evolved over time and responded to government priorities, external events, and public perceptions and fears about those events. As the policy continues to evolve, we hope that this book, and the kind of research it offers, will encourage policy-makers to take account of the way the policy is enacted and of the multiple effects it has on educators, children and young people and others. The conclusions we have outlined in this chapter indicate some of the insights that can be gleaned from attending to the voices of those in the education sector affected by the Prevent Duty, and suggest aspects of the policy that can be improved. This does not ignore the debates about whether the Duty is the right kind of policy in the first place, but it does suggest that, if the Duty continues, there are some pragmatic steps that should be taken to avoid or minimise unintended harm. We hope such pragmatic suggestions will inform the next steps of those leading the development of policy at national level, as well as those enacting policy through their roles in the education system.

\section{References}

Anderson, R. (2007). Thematic content analysis (TCA): Descriptive presentation of qualitative data. Retrieved from www.wellknowingconsulting.org/publications/pdfs/ThematicContentAnalysis.pdf

Awan, I., Spiller, K., \& Whiting, A. (2018). Terrorism in the classroom: Security, surveillance and a public duty to act. Basingstoke, UK: Palgrave Pivot.

Bajaj, M. (2012). Schooling for social change: The rise and impact of human rights education in India. London: Continuum.

Ball, S. J., Maguire, M., \& Braun, A. (2013). How schools do policy. Abingdon, UK: Routledge. 
Garland, D. (1996). The limits of the sovereign state: Strategies of crime control in contemporary society. The British Journal of Criminology, 36(4), 445-471. Heath-Kelly, C., \& Strausz, E. (2019). The banality of counterterrorism "after, after 9/11"? Perspectives on the Prevent duty from the UK health care sector. Critical Studies on Terrorism, 12(1), 89-109.

Lipsky, M. (2010). Street-level bureaucracy: Dilemmas of the individual in public services. New York: Russell Sage Foundation.

McGlynn, C., \& McDaid, S. (2019). Radicalisation and counter-radicalisation in higher education. Bingley, UK: Emerald.

Thomas, P. (2017). Changing experiences of responsibilisation and contestation within counter-terrorism policies: The British Prevent experience. Policy and Politics, 45(3), 305-322.

Vincent, C. (2019). Tea and the queen: Fundamental British values, schools and citizenship. Bristol, UK: Policy Press.

Open Access This chapter is licensed under the terms of the Creative Commons Attribution 4.0 International License (http://creativecommons.org/licenses/ by/4.0/), which permits use, sharing, adaptation, distribution and reproduction in any medium or format, as long as you give appropriate credit to the original author(s) and the source, provide a link to the Creative Commons licence and indicate if changes were made.

The images or other third party material in this chapter are included in the chapter's Creative Commons licence, unless indicated otherwise in a credit line to the material. If material is not included in the chapter's Creative Commons licence and your intended use is not permitted by statutory regulation or exceeds the permitted use, you will need to obtain permission directly from the copyright holder.

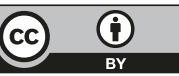

